\title{
Biologically induced differences in erodibility and aggregation of subtidal and intertidal sediments: a possible cause for seasonal changes in sediment deposition
}

\author{
T.J. Andersen ${ }^{a, *}$, L.C. Lund-Hansen ${ }^{b}$, M. Pejrup ${ }^{a}$, K.T. Jensen ${ }^{b}$, K.N. Mouritsen ${ }^{b}$ \\ ${ }^{\mathrm{a}}$ Institute of Geography, University of Copenhagen, Øster Voldgade 10, 1350 Copenhagen K, Denmark \\ ${ }^{\mathrm{b}}$ Department of Marine Ecology, Institute of Biological Sciences, University of Aarhus, Finlandsgade 14, 8200 Aarhus, Denmark
}

Received 11 December 2002; accepted 24 September 2004

Available online 24 November 2004

\begin{abstract}
This study was carried out to describe the difference in erodibility and aggregation in a tidal basin including both subtidal and intertidal study sites and to use these results to explain the shifting erosion/deposition cycles at the sites. Erosion thresholds, erosion rates and settling velocities of the eroded material were measured at a mudflat transect and at sediment cores taken from a nearby tidal channel during surveys made in May 2000 and March 2002. Surface samples were analysed for grain-size, chl. $a$ content, faecal pellet content, dry bulk density and organic content. Additionally, surface samples were taken at eight occasions in the period January 2002 to May 2003 from shallow tidal channels in the area. These samples were analysed for mud content and showed that major shifts in sediment distribution occurred in the period. The erodibility of the mudflat was generally high due to pelletization by the mudsnail Hydrobia ulvae but close to the salt marsh much lower erodibility was found, probably due to stabilisation by microphytobenthos. In contrast, the erodibility of the channel bed seemed to be very little influenced by biological activity and the relatively low erodibility found here was caused by physical characteristics of the sediment. The sediment eroded from the mudflat was generally strongly pelletized and showed high settling velocities whereas less aggregation and lower settling velocities were found for the channel bed sediments. Temporal variations of the mudflat stability and hydrodynamics resulted in temporal variations of deposition and erosion and the changing stability at the mudflat is likely to be one of the main reasons for a general transport of fine-grained sediment from the mudflat to the channel in the cold seasons and vice versa during the rest of the year.
\end{abstract}

(C) 2004 Elsevier B.V. All rights reserved.

Keywords: Erosion threshold; Erosion rate; Sedimentation; Deposition; Hydrobia ulvae; Seasonality; The Wadden Sea; Denmark

\footnotetext{
* Corresponding author. Tel.: +45353225 03; fax: +453532 2501 .

E-mail address: tja@geogr.ku.dk (T.J. Andersen).
} 


\section{Introduction}

The erosion, transport and deposition of finegrained cohesive sediments in the marine environment have been the focus of numerous studies. Some of the reasons have been that various pollutants, heavy metals and fertilisers tend to stick to the fine material and also that intertidal, fine-grained deposits are important habitats for both macrozoobenthos, birds and fishes. Key-parameters for the transport of cohesive sediments are the critical bed shear stress for erosion (the erosion threshold), the erosion rate and the settling velocity of the material. None of these parameters are easily predicted on the basis of grainsize distributions, both due to the cohesive nature of the sediment and the generally strong biological interaction in the important processes (e.g., Rhoads, 1974; Nowell et al., 1981; Widdows and Brinsley, 2002). Consequently, detailed field-studies have to be undertaken and measurements generally have to be made in situ in order to avoid disturbance of the sediment surface or disruption of sediment flocs. With respect to sediment erodibility, several studies have tried to evaluate and sometimes quantify the effect of microphytobenthos (e.g., Paterson, 1989; Yallop et al., 1994) or dominant macrozoobenthic species (e.g., Macoma balthica (Willows et al., 1998; Widdows et al., 2000), Corophium volutator (Mouritsen et al., 1998; de Deckere et al., 2000) and Hydrobia ulvae (Blanchard et al., 1997; Austen et al., 1999; Andersen, 2001a)). These studies have all shown that both microphytobenthos and macrozoobenthos may have a significant influence on the erodibility of cohesive sediments. Mudflat stabilisation has been well-documented for epipelic benthic diatoms (Paterson, 1989; Yallop et al., 1994; Riethmüller et al., 2000) which secrete extracellular polymeric substances (EPS) during locomotion (Admiraal, 1984). Although the exact mechanism of sediment stabilisation by diatoms and EPS still is a matter of debate (Stal, 2003), numerous in situ studies have documented that erosion thresholds generally increase significantly when epipelic diatoms are present in high numbers in fine-grained sediments. Macrozoobenthos on the other hand generally destabilise the sediment surface by bioturbation, creation of surface tracks and by sediment aggregation (Nowell et al., 1981). An indirect but sometimes very important destabilising effect of some macrozoobenthic species is due to grazing on benthic diatoms (Gerdol and Hughes, 1994; de Deckere et al., 2000).

Previous studies on sediment erodibility have generally focussed on either subtidal or intertidal sediments whereas, to the knowledge of the authors, only one previous study (Amos et al., 1997) has included data from both sedimentary systems. Their study on sediments from the Fraser River Delta showed only minor differences between subtidal and intertidal sediments with respect to erodibility. However, with an increasing amount of reports of biological effects on erodibility of fine-grained sediments, it seems likely that major differences between sub- and intertidal sediments may exist at places. This is due to differences in both species abundance and community structure between intertidal and subtidal sites. Microphytobenthos are restricted to the intertidal or shallow subtidal zone in turbid waters (e.g., estuaries and coastal lagoons) due to lack of light available for photosynthesis in deeper water. This implies that the biostabilization brought about by diatoms will mainly be restricted to the intertidal zone. Differences in macrozoobenthic communities along shore-gradients are also common (Reise, 1985) and this will also result in differences in aggregation and erodibility of the sediment bed. The main hypothesis and background for the onset of this study was that such differences do exist and that they need to be quantified in order to make models and predictions of the transport of cohesive sediment in estuaries and coastal lagoons more reliable.

Additionally, temporal changes in the erodibility of intertidal sediments have been reported (e.g., Underwood and Paterson, 1993; Widdows et al., 2000; de Brouwer et al., 2000; Andersen, 2001a) and these changes may potentially play a major role in the seasonal variations in sedimentation and erosion which are frequently found on intertidal mudflats (e.g., Christie et al., 1999; O'Brien et al., 2000; Andersen and Pejrup, 2001; De Deckere et al., 2002). Consequently, an additional purpose of the present study has also been to examine the temporary, muddy deposits which were found on sub- and intertidal positions during the study and to present a hypothesis that may explain the occurrence of these deposits. 


\section{Study site}

The investigation sites are situated in the microtidal Rømø Bight (Fig. 1) which is part of the Lister Dyb tidal basin. The tidal range is $1.8-2.0 \mathrm{~m}$ and the water column is well mixed due to low freshwater inflow and frequent mixing by windwaves. The sediment in the tidal basin is generally sandy but muddy sediments are found in the sheltered parts of the basin. A causeway connecting the barrier island Rømø with the mainland was finished in 1948 and fine-grained sediments have accumulated in large parts of Rømø Bight since then. A sediment budget for Lister Dyb tidal basin has been set up by Pejrup et al. (1997) and the budget showed that about $65 \%$ of the fine-grained material accumulating in the basin is imported from the North Sea.

Two main investigation sites were chosen in Rømø Bight - a mudflat site and a small tidal channel. Both sites have been studied in detail recently and data on seasonal bed-level changes, suspended sediment

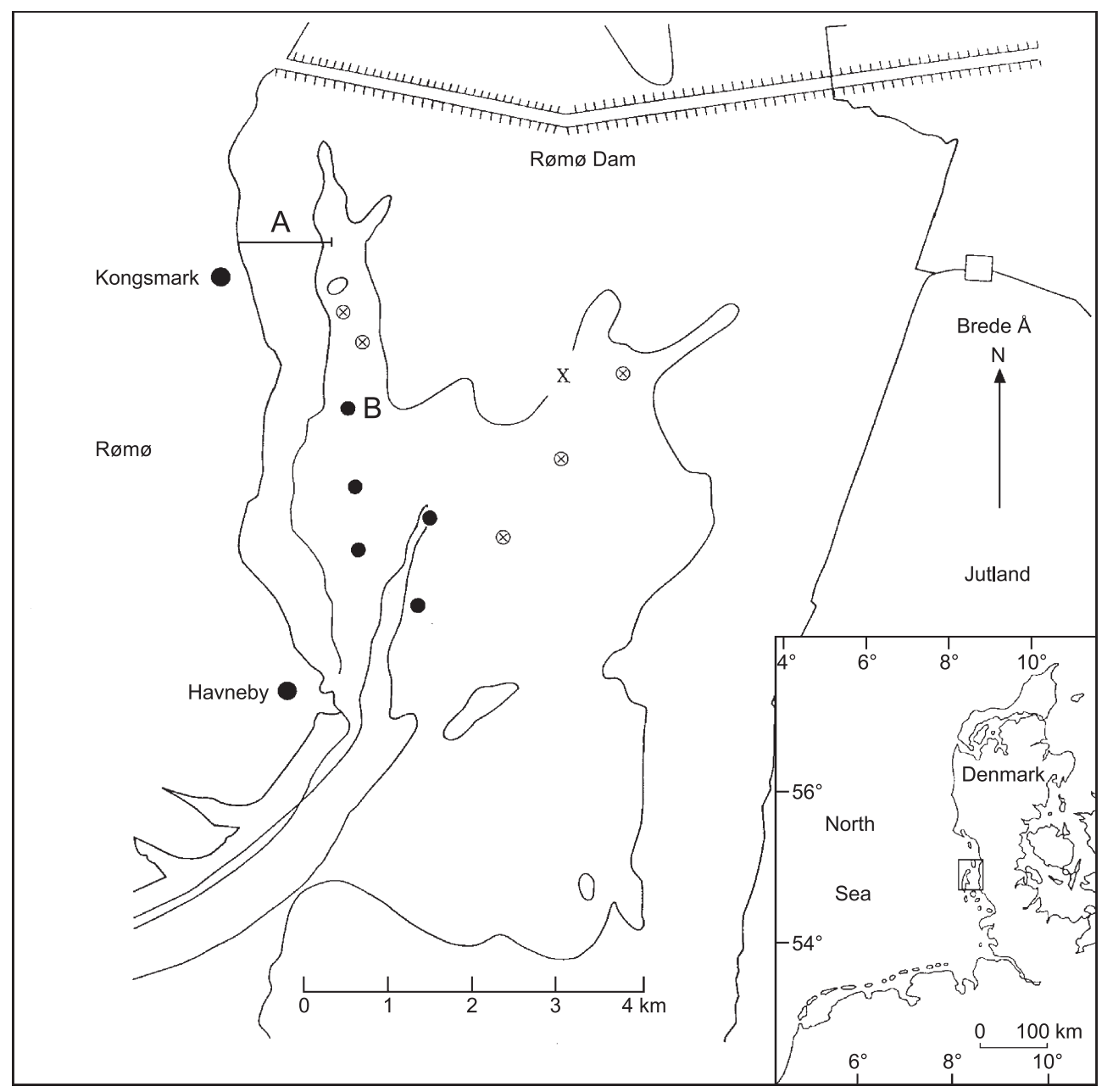

Fig. 1. Map of the study area. The transect at the mudflat at Kongsmark is shown (marked A) as well as the intertidal sampling positions. Filled circles represent stations with significant temporal changes in mud content, open circles stations with insignificant changes. Station with subtidal EROMES measurements is marked B. Line marked X: mean low water spring tide. 
transport, erodibility and ${ }^{210} \mathrm{~Pb}$-dating have been reported by Andersen and Pejrup $(2001,2002)$ and Andersen (2001a,b). Both study sites show net accumulation (inferred form ${ }^{210} \mathrm{~Pb}$ and ${ }^{137} \mathrm{Cs}$ dating) of about $15 \mathrm{~mm}$ year $^{-1}$ (Andersen and Pejrup, in prep.).

Maximum current velocities at the mudflat, situated at the eastern (sheltered) side of Rømø at Kongsmark, are only about $30 \mathrm{~cm} \mathrm{~s}^{-1}$ and in the tidal channel about $50 \mathrm{~cm} \mathrm{~s}^{-1}$ (measured $50 \mathrm{~cm}$ above the bed). However, wind-generated waves often cause erosion of the bed at the mudflat as shown by numerous time-series records of the suspended sediment transport (Andersen and Pejrup, 2001). The mudflat site is very fine-grained with a sand content mostly below $2 \%$ and the bed is the host for a large macrozoobenthic population including the bivalves Cardium edule, M. balthica and Mytilus edulis, the polychaete Nereis diversicolor and the prosobranch H. ulvae. The snail H. ulvae is present in very large numbers at most of the Kongsmark mudflat and has been shown to be the main factor controlling the erodibility and aggregation of the bed material when present (Andersen, 2001a; Andersen and Pejrup, 2002). The channel site, situated in Fuglegroeften about $3.6 \mathrm{~km}$ south of the mudflat, is mainly composed of sandy and mixed sediments and the macrozoobenthic community is very sparse with only few polychaetes and bivalves present. Only very small individuals (about $0.5 \mathrm{~mm}$ shell length) of H. ulvae were present. Consequently, the material is not subject to significant bioaggregation at this site and the few bioaggregates in the sediments are likely to have been formed at the surrounding tidal flats.

Both the mudflat and the tidal channel site were visited in May 2000 and March 2002 in order to give information about a winter/early spring situation (March) and late spring/early summer situation (May). The two sites sampled in the tidal channel were within a distance of $400 \mathrm{~m}$ of each other and sampling was done at random within a distance of approximately $100 \mathrm{~m}$ of the positions. The sampling at the mudflat was performed at a transect, which has been surveyed for different purposes since 1996. It is perpendicular to the salt marsh front and stations 20, $150,225,400$ and $500 \mathrm{~m}$ from the salt marsh were visited.

\section{Methods}

\subsection{Bed samples}

A surface scrape of the topmost 1-2 mm of the bed was analysed for grain-size, faecal pellet content and organic content. Additional samples of the topmost 5 $\mathrm{mm}$ of the bed were taken with a syringe (diameter 21 $\mathrm{mm}$, four samples pooled into one sample) and analysed for chl. $a$ content and dry bulk density (these samples were omitted at the channel site in March 2000). The samples were stored at $5{ }^{\circ} \mathrm{C}$ and analysed within $48 \mathrm{~h}$ except for a few situations in which analysis within $48 \mathrm{~h}$ were logistically not possible. In these cases, the samples were stored at $-18^{\circ} \mathrm{C}$ until analysis.

Grain size analyses were carried out by use of a Malvern Mastersizer/E laser-sizer after careful dispersion in $0.01 \mathrm{M} \mathrm{Na}_{2} \mathrm{P}_{4} \mathrm{O}_{7}$ and ultrasonic treatment for two min at $20 \mathrm{kHz}, 180 \mathrm{~W}$ prior to analysis. The chl. $a$ and phaeopigment contents were determined spectrophotometrically after extraction in $90 \%$ acetone for $24 \mathrm{~h}$ at $5{ }^{\circ} \mathrm{C}$ in darkness. After centrifugation at $3000 \mathrm{rpm}$ for $15 \mathrm{~min}$, the absorbance of the supernatant at 665 and $750 \mathrm{~nm}$ was measured before and after acidification with $200 \mu \mathrm{l}$ of $1 \mathrm{M} \mathrm{HCl}$ and calculations were based on Parsons et al. (1984). The faecal pellet content of the bed material and calibration samples for the optical backscatter sensor (OBSsensor) were determined by gentle wet-sieving of a sub-sample at $63 \mu \mathrm{m}$ and examination of the retained material under microscope in order to estimate the faecal pellet content in this material (generally $>90 \%$ for the mudflat and $<10 \%$ for the tidal channel). The retained material was subsequently given an ultrasonic treatment for $2 \mathrm{~min}$ and wet-sieved at $63 \mu \mathrm{m}$ again in order to retain sand and shell-fragments. The faecal pellet contents are minimum values since small pellets and sand grains incorporated into pellets are excluded when using this method.

Preliminary investigations have indicated that large temporal variations in the mud-content of the channel-bed may occur and a sampling program was set up in order to examine this in more detail. Bed samples were taken with a Van-Veen grab at fixed positions in the tidal channel and the samples were analysed for grain-size and faecal pellet content. Four stations were visited in Fuglegroeften in January and the sampling program was extended to 
include 16 other positions at subtidal positions within the rest of Rømø Bay in March, August, November and December in 2002, and March and May in 2003 (Fig. 1). Some of the positions showed lag-sediments dominated by shell-debris and grainsize analysis was not undertaken on these samples. Only samples with measured mud-contents are discussed in this paper and shown on Fig. 1.

\subsection{Erosion/settling experiments}

The erosion experiments were carried out using a portable EROMES erosion equipment (originally described by Schünemann and Kühl, 1991 and the portable version described in detail by Andersen, 2001a). Basically, the instrument consists of a 100$\mathrm{mm}$ diameter perspex tube, which is pushed into the undisturbed bed sediment. The tube is gently filled with local water and the eroding unit is placed on top of the tube. This eroding unit consists of a propeller, which generates bed shear stresses, and an OBSsensor, which monitors the changing suspended sediment concentration (SSC). The propeller revolutions are transferred to bed shear stress by use of a calibration based on the onset of erosion of quartz sands with known critical erosion shear stress (Schünemann and Kühl, 1991; Andersen, 2001a). Additionally, the bed shear stress has been measured directly by use of a hot-film probe at different radii within the instrument (Andersen, 2001a).

The instrument was brought onto the mudflat and experiments were carried out during low-water at stations 20,150, 225, 450 and $500 \mathrm{~m}$ from the salt marsh. One experiment was performed for each station. Additionally, two experiments were carried out $800 \mathrm{~m}$ from the salt marsh in May 2000. Experiments from the stations 150, 225, 450 and 500 showed similar erosion behaviour and the data from these stations were pooled and treated as four replicates. In the tidal channel, box-core samples were taken with a hydraulic dampened box-corer (Lund-Hansen et al., 2001), which is designed to take undisturbed sediment samples for, e.g., erodibility measurements (data from some of these investigations have been presented by Christiansen et al., 2002; Lund-Hansen et al., 2002). When brought to the deck of the research vessel, one or two 10-cm diameter cores where taken from an undisturbed surface and EROMES measurements where undertaken onboard the ship within less than $3 \mathrm{~h}$. In total, eight erosion experiments were carried out during each of the two investigations in the tidal channel.

During each erosion experiment at the mudflat, the bed shear stress was increased in steps of $0.1 \mathrm{~N} \mathrm{~m}^{-2}$ every 2 min from $0.1 \mathrm{~N} \mathrm{~m}^{-2}$ to 0.5 or $1.0 \mathrm{~N} \mathrm{~m}^{-2}$ (depending on the erosion threshold of the bed). The erosion rate at each step is initially high at the mudflat but quickly drops and generally approaches zero after 2-5 min. The bed shear stress was maintained for 10 min at the 0.5 and $1.0 \mathrm{~N} \mathrm{~m}^{-2}$ step for the experiments in March 2002 in order to reach a situation with zero erosion rate. At the channel site, longer time steps were needed before the erosion decreased and time steps of 5 min were chosen with steps of 15-20 min for the 0.5 and $1.0 \mathrm{~N} \mathrm{~m}^{-2}$ increments. The erosion rates, which are reported and compared here, are the initial $5 \mathrm{~min}$ averages after application of bed shear stresses of 0.5 and $1.0 \mathrm{~N} \mathrm{~m}^{-2}$. The erosion thresholds were determined by use of plots of erosion rates versus applied bed stress. A linear fit was made through the data points in the region of the onset of erosion and the threshold was determined as the bed shear stress at the intercept of this line with a critical erosion rate. A critical erosion rate of $0.1 \mathrm{~g} \mathrm{~m}^{-2} \mathrm{~s}^{-1}$ was used as this was appropriate when discrimination should be made between the erosion of the fluffy top-layer and the erosion of the bed itself. Consequently, the reported thresholds are the critical bed shear stresses for the erosion of the material below the fluff-layer and not the threshold for erosion of the fluff itself (if fluff was present).

In order to gain information on the aggregation and settling velocity of the eroded material, the propeller was turned off after the 0.5 and $1.0 \mathrm{~N} \mathrm{~m}^{-2}$ steps and the suspended material was allowed to settle. After the continued monitoring of the change in SSC at a fixed level below the water surface $(9 \mathrm{~cm})$ it is possible to calculate the settling velocity distribution of the eroded material.

Samples for the calibration of the OBS-sensor were withdrawn from the instrument during each experiment and filtered through pre weighed Millipore 0.45 $\mu \mathrm{m}$ filters or $0.7 \mu \mathrm{m}$ Whatmann GF/F filters. Samples were taken both during erosion and settling phases. An example from the mudflat is given in Fig. 2. The regression coefficients were high $\left(r^{2}=0.97\right)$. Both samples taken during erosion and settling are shown 


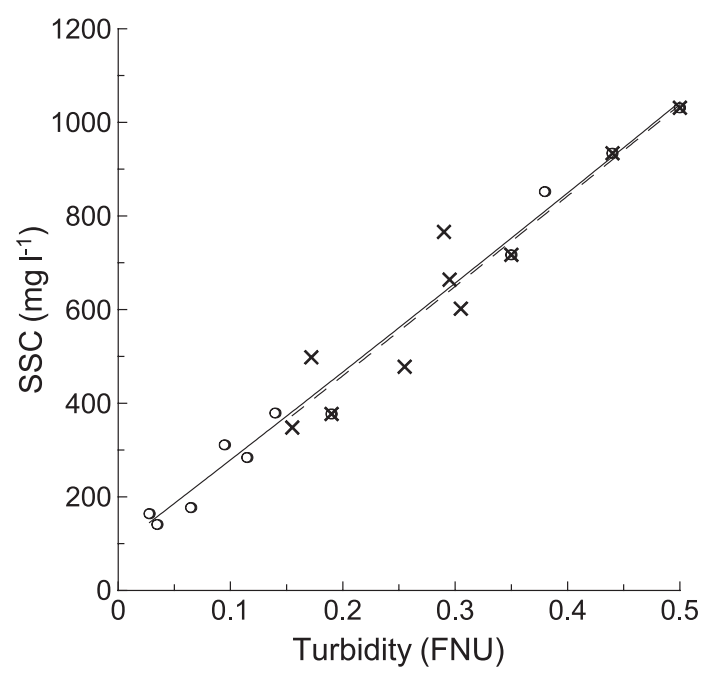

Fig. 2. Example of OBS-calibration, mudflat March 2002. $\mathrm{O}=$ calibration samples during erosion phase, $\mathrm{X}=$ calibration samples during settling phase. Solid line=best second degree polynomial fit to erosion phase. Broken line=best second degree polynomial fit to settling phase.

and the regression lines from the two phases did not differ significantly. This is caused by the fine texture of the material. Settling experiments on mixed sediments with higher sand contents will be impeded due to divergence of the calibrations during erosion and deposition.

Due to the short duration of the settling experiments (generally $<10 \mathrm{~min}$ ) and only a weak dependence of settling velocity on the initial suspended sediment concentration, it is concluded that flocculation during the settling experiments is of very limited importance (Andersen and Pejrup, 2002). In order to make the data directly comparable (compen- sate for the changing viscosity of the water with changing temperature), the settling velocities were recalculated to a common $20{ }^{\circ} \mathrm{C}$ temperature by use of Stokes' law. It should be noted that Stokes' law is only strictly applicable for grains/aggregates in the silt and clay range but only minor errors are found up to a Reynolds number of about 5 (Eisma, 1993). This corresponds to a grain-size of about $200 \mu \mathrm{m}$ at $10{ }^{\circ} \mathrm{C}$, which is about twice as large as the largest grains brought into suspension during this study.

The sediment on some of the Millipore filters was later analysed for grain-size. The Whatmann filters were combusted at $550{ }^{\circ} \mathrm{C}$ for $2 \mathrm{~h}$ in order to determine organic content by loss on ignition (LOI).

\subsection{Macrozoobenthos}

Macrozoobenthos from each of the EROMES erosion cores (surface area $78.5 \mathrm{~cm}^{-2}$ ) were counted after sieving of the sediment through a $500-\mu \mathrm{m}$ sieve.

\subsection{Statistical analysis}

The statistical analysis was carried out using the Statistical Package for the Social Sciences (SPSS).

\section{Results}

\subsection{Bed level}

Bed-level data representing the major part of the Kongsmark mudflat (400 and $500 \mathrm{~m}$ stations) showed general erosion during spring 2002 and strong accumulation during the summer 2002 (Fig. 3; for

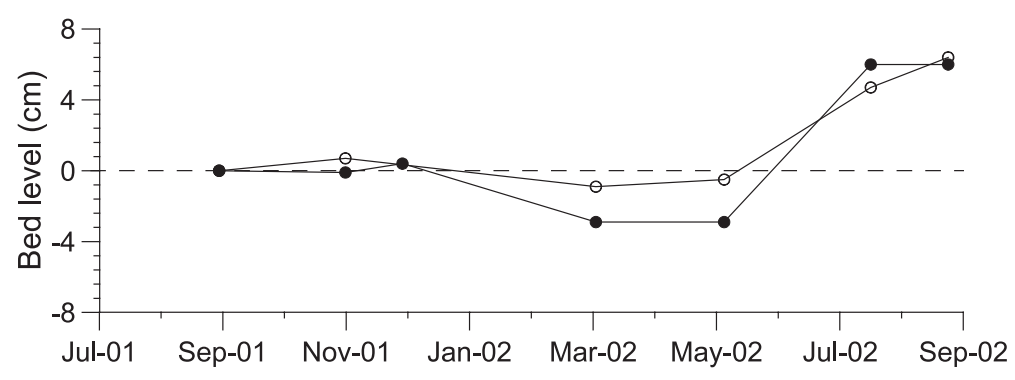

Fig. 3. Measured bed-level changes at the mudflat during the period September 2001-September 2002. Open circles=400 m station. Filled circles $=500 \mathrm{~m}$ station. 


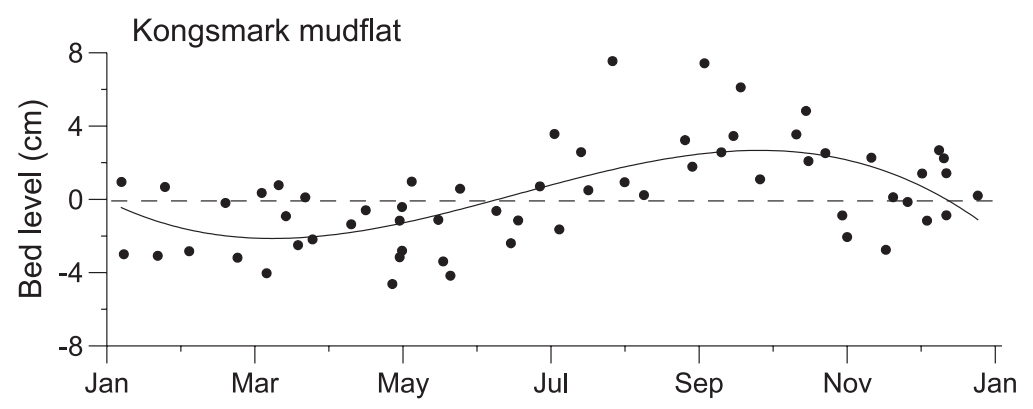

Fig. 4. Seasonal variation of bed level at the mudflat transect, $500 \mathrm{~m}$ station. Solid line=best third degree polynomial fit to the data.

method and longer time-series, see Andersen and Pejrup, 2001). In order to check if this is accidental, the bed-level data from the period 1997-2002 were plotted after correction for the long-term net-increase in bed-level (Fig. 4). The figure clearly shows a similar tendency with low bed-levels (erosion) in spring and high bed-levels (deposition) in summer/ early autumn.

\subsection{Bed material}

The bed material at the mudflat was very finegrained with a mean grain-size of about $6 \mu \mathrm{m}$ and a sand content below 2\%. No significant spatial or temporal variations were found. In contrast, the bed material in the channel was sandier and larger spatial and temporal variations were present. Five of the 10 positions with measured mud contents (Fig. 1) showed only minor temporal variations but five showed a significantly higher mud content in March 2002 compared to all other sampling periods (Fig. 5, $p<0.014$ ). The mud content of the top 5 $\mathrm{mm}$ of the bed increased from $17 \%$ in January 2002 to $59 \%$ in March, and then decreased to $9 \%$ in August. Low contents between $11 \%$ and $16 \%$ were observed during the rest of the sampling period. A significant increase in mud content was not observed in spring 2003 although two stations

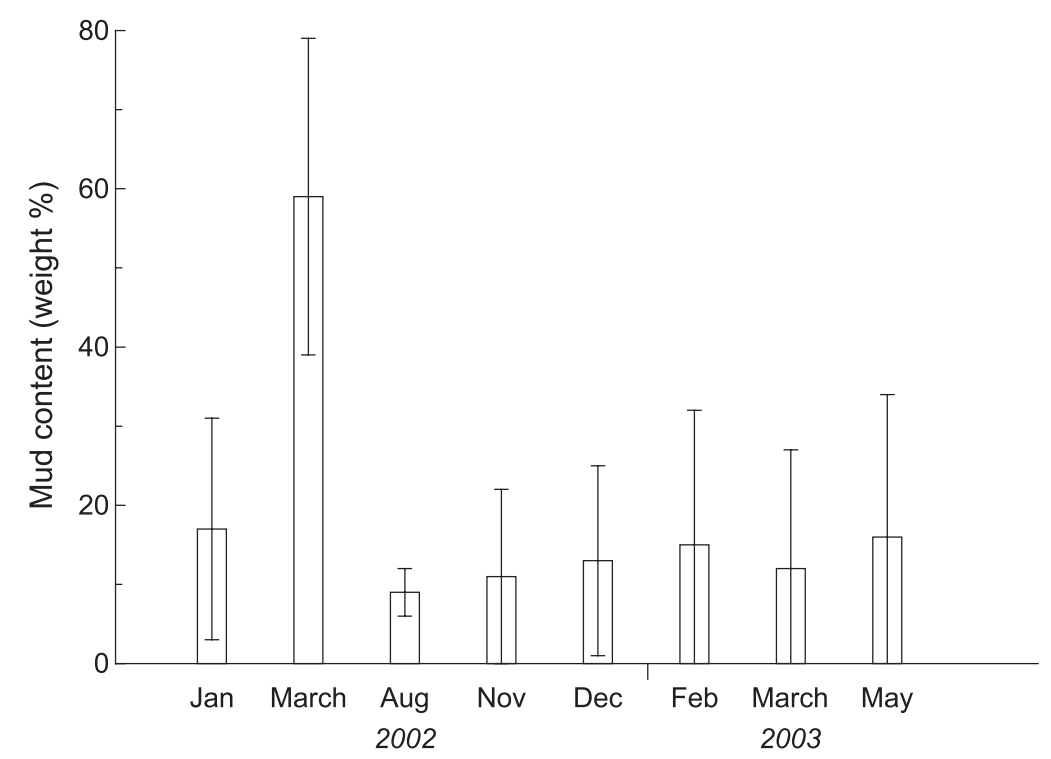

Fig. 5. The temporal variation of the mud-content for the bed-sediment found in the tidal channels in the period January 2002-May 2003 (stations marked with filled circles in Fig. 1). Error bars: average \pm STD. 
showed a $50-100 \%$ increase in February and March 2003 compared to the value in November 2002.

The mean grain-size at the position for erosionexperiments visited in May 2000 was $107 \mu \mathrm{m}$ with a mud content of about $16 \%$. The site was muddier in March 2002 with a mean grain size of $29 \mu \mathrm{m}$ and a mud content of about $60 \%$. The difference in texture caused differences in dry bulk densities and organic contents and the dry bulk density in the channel (average $0.47 \mathrm{~g} \mathrm{~cm}^{-3}$ in May 2002) was significantly higher than at the mudflat (average $0.31 \mathrm{~g}$ $\mathrm{cm}^{-3}$ ) and the organic content was about twice as high at the mudflat as in the channel $(11 \%$ and $6 \%$, respectively).

The macrofaunal community at the two sites are listed in Tables 1 and 2 (data from May 2000). The mudflat was dominated by very high densities of $H$. ulvae and a pronounced cross-shore variation was observed with low densities of $H$. ulvae close to the salt marsh and at the most seaward station and high densities at the rest of the transect. Much lower densities of macrofauna were found in the tidal channel. Only minor differences between the two visits were observed both at the mudflat and in the tidal channel.
Table 2

Mean density (ind. $\mathrm{m}^{-2}, n=8$ ) of macrozoobenthic species within the EROMES-cores from the channel (May 2000)

\begin{tabular}{lr}
\hline Oligochaeta & 1529 \\
Tubificoides benedeni & \\
Polychaeta & 13 \\
Autolytus sp. & 127 \\
Nephthys sp. & 51 \\
Scoloplos armiger & 13 \\
Eteone longa & 13 \\
Polydora sp. & 64 \\
Pygospio elegans & 38 \\
Spionidae & 102 \\
Streblospio shrubsoli & 1,134 \\
Cirratulidae sp. & 13 \\
Ampharetidae & \\
Gastropoda & \\
Hydrobia ulvae & 242 \\
Bivalvia & \\
Macoma balthica & \\
Mya arenaria & 13 \\
Mytilus edulis & 38 \\
Ensis americanus & 25 \\
Crustacea & \\
Cumacea & \\
Gammaridea & 25 \\
& 13
\end{tabular}

Table 1

Density of macrozoobenthic species within the EROMES-cores (ind $\mathrm{m}^{-2}$ ) from the mudflat at Kongsmark (May 2000) taken at different distances from the salt marsh (+: presence of fragments)

\begin{tabular}{|c|c|c|c|c|c|c|c|}
\hline & $20 \mathrm{~m}$ & $150 \mathrm{~m}$ & $225 \mathrm{~m}$ & $450 \mathrm{~m}$ & $575 \mathrm{~m}$ & $800(1) \mathrm{m}$ & $800(2) \mathrm{m}$ \\
\hline \multicolumn{8}{|l|}{ Oligochaeta } \\
\hline Tubificoides benedeni & 11,465 & 9682 & 6242 & 3439 & 1911 & 1274 & 1656 \\
\hline \multicolumn{8}{|l|}{ Polychaeta } \\
\hline Hediste diversicolor & 637 & 127 & 510 & 0 & 0 & 0 & 0 \\
\hline Pygospio elegans & 255 & 0 & 637 & 0 & 0 & 0 & 0 \\
\hline Streblospio sp. & 0 & 255 & 0 & 0 & 0 & 0 & 0 \\
\hline Cirratulidae sp. & 510 & 510 & 255 & 3822 & 11,975 & 11,847 & 7516 \\
\hline Heteromastus filiformis & 0 & 0 & 0 & 0 & 0 & 0 & + \\
\hline Notomastus sp. & 0 & 0 & 0 & 0 & 0 & 0 & 255 \\
\hline \multicolumn{8}{|l|}{ Gastropoda } \\
\hline Hydrobia ulvae & 28,662 & 74,650 & 147,134 & 138,471 & 180,382 & 4586 & 11,592 \\
\hline \multicolumn{8}{|l|}{ Bivalvia } \\
\hline Cerastoderma edule & 0 & 0 & 0 & 127 & 127 & 0 & 0 \\
\hline Macoma balthica & 0 & 255 & 0 & 382 & 0 & 0 & 0 \\
\hline Mya arenaria & 0 & 255 & 127 & 127 & 0 & 0 & 0 \\
\hline Mytilus edulis & 0 & 0 & 0 & 0 & 0 & 0 & 127 \\
\hline
\end{tabular}


There were no significant differences in the chl. $a$ content at the mudflat dominated by $H$. ulvae and the channel in March 2002 (45 and $47 \mathrm{mg}$ $\mathrm{m}^{-2}$, respectively) and generally only minor and unsystematic seasonal changes have been observed at the mudflat sites dominated by $H$. ulvae (Andersen, 2001a). The chl. a content was higher in May 2000 at the mudflat dominated by $H$. ulvae (average $90 \mathrm{mg} \mathrm{m}^{-2}$ ), but unfortunately chl. $a$ content was not measured in the tidal channel at this time. However, biofilms were not present at the channel sediments and consequently the sediment did not show any marked influence of microphytobenthos. The chl. a content was high at the mudflat station closest to the salt marsh (20 $\mathrm{m}$ from the salt marsh) in both May 2000 (177 $\mathrm{mg} \mathrm{m}{ }^{-2}$ ) and March $2002\left(65 \mathrm{mg} \mathrm{m}^{-2}\right)$, indicating that this station had a dense population of microphytobenthos.

The faecal pellet content was very low in the tidal channel both in May 2000 and March 2002 (3\% and $0 \%$ by mass, respectively) and also low at the mudflat in March (6\%). However, in May, the faecal pellet content was on average $57 \%$ at the mudflat sites dominated by $H$. ulvae, which is consistent with the general seasonal variation at the site with high contents in the warmer seasons and low contents during winter (Andersen, 2001a). The pellet content was lower at the station closest to the salt marsh (25\% in May 2000 and 1\% in March 2002).

\subsection{Erodibility-spatial and temporal variation}

Some pronounced differences between the erodibility and aggregation at the mudflat and the tidal channel were obvious from the field-studies. The erosion thresholds were generally higher in the tidal channel than at the mudflat and the erosion rates were lower. The innermost station at the mudflat showed high contents of chl. $a$ indicating high contents of microphytobenthos and the erosion thresholds were high at this site $\left(>1 \mathrm{~N} \mathrm{~m}^{-2}\right.$ in May 2000 and $1.55 \mathrm{~N} \mathrm{~m}^{-2}$ in March 2002). Accordingly, the erosion rates at $0.5 \mathrm{~N} \mathrm{~m}^{-2}$ were very low (0.02 and $0.00 \mathrm{~g} \mathrm{~m}^{-2} \mathrm{~s}^{-1}$, respectively). This confirms previous investigations which have shown reduced erodibility at sites with high contents of microphytobenthos (e.g., Paterson, 1989). There were no indications that the differences were due to longer subarial exposure (the wet and dry bulk densities were not higher at this site). This can also be confirmed by comparison with the most seaward station ( $800 \mathrm{~m}$ from the salt marsh), which has the shortest exposure period during each tide. The station was visited in May 2000 and on some other occasions in 1999 and 2000 and showed very low density of $H$. ulvae but chl. a contents and erosion thresholds comparable to the $20-\mathrm{m}$ station. However, due to the covariation between chl. $a$ contents and density of $H$. ulvae, it is only possible to conclude that the low erodibility at the station close to the salt marsh probably was caused by a combination of both microphytobenthic stabilisation and reduced bioturbation by macrozoobenthos.

The data from the tidal channel and the mudflat is compared below but the mudflat station closest to the shore has been omitted as this station was only representative for a small part of the tidal flat and showed faecal pellet contents, chl. $a$ contents and erodibility that were distinctly different from the major part of the mudflat (see above). The $p$-values are based on Student's $t$-test.

\subsection{Erosion threshold}

The measured erosion thresholds in the channel were not significantly different in 2000 and 2002 (0.65 and $0.73 \mathrm{~N} \mathrm{~m}^{-2}$, respectively; Fig. 6). Similarly, thresholds were not different for the two visits at the mudflat $\left(0.28 \mathrm{~N} \mathrm{~m}^{-2}\right.$ in May 2000 and 0.35 in March 2002). However, the thresholds were significantly different for the channel and mudflat sites $(p<0.001)$ during both field trips and on average more than twice as high at the channel site than at the mudflat $(0.70$ and $0.31 \mathrm{~N} \mathrm{~m}^{-2}$, respectively).

\subsection{Erosion rate}

The erosion rates at $0.5 \mathrm{~N} \mathrm{~m}^{-2}$ were low in the channel (average $0.05 \mathrm{~g} \mathrm{~m}^{-2} \mathrm{~s}^{-1}$ ). The erosion rate was also low at the tidal flat in March $2002(0.11 \mathrm{~g}$ $\mathrm{m}^{-2} \mathrm{~s}^{-1}$ ) and not significantly different from the channel (Fig. 7). However, in May 2000, the erosion rate was higher (mean $=0.58 \mathrm{~g} \mathrm{~m}^{-2} \mathrm{~s}^{-1}$ ) and was significantly different from both the 


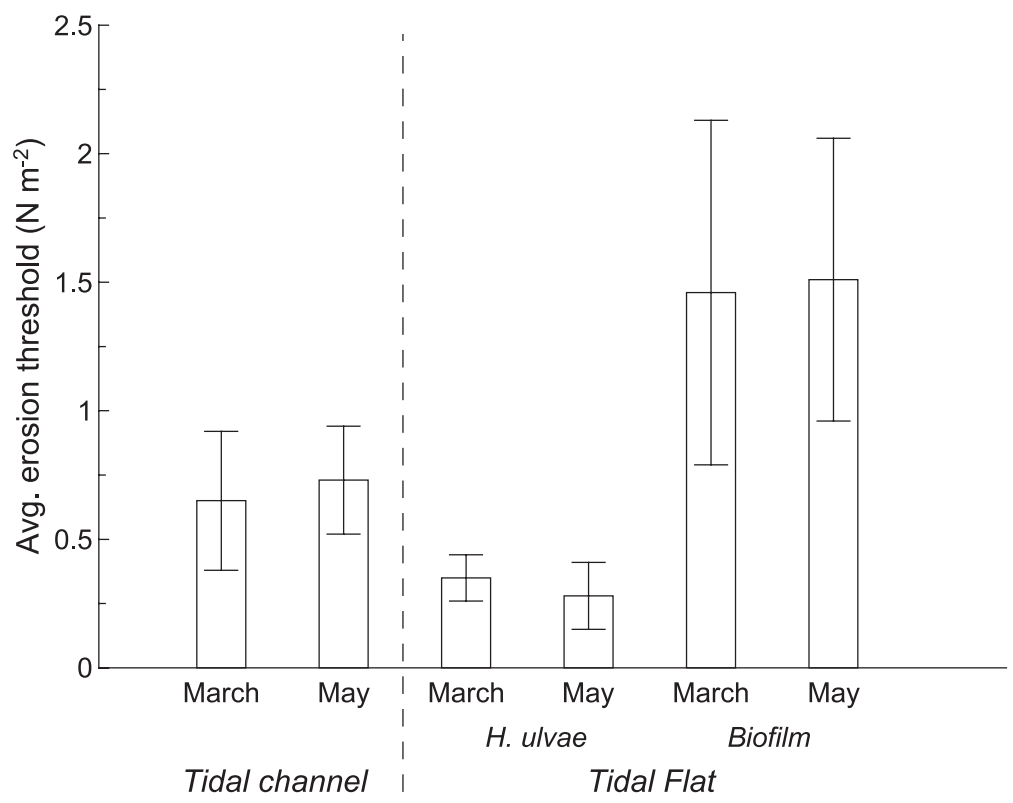

Fig. 6. Erosion thresholds measured in the tidal channel $(n=8)$ and at the mudflat. The mudflat data is split into two groups: the sites dominated by $H$. ulvae $(n=4)$ and the sites dominated by microphytobenthos $(n=3)$. Error bars: average \pm STD.

channel site $(p<0.001)$ and the mudflat in March $2002(p=0.02)$. The average 5-min erosion rate at $1.0 \mathrm{~N} \mathrm{~m}^{-2} \mathrm{~s}^{-1}$ at the mudflat was $0.47 \mathrm{~g} \mathrm{~m}^{-2} \mathrm{~s}^{-1}$ in March 2002 and significantly higher than in the tidal channel $\left(0.05 \mathrm{~g} \mathrm{~m}^{-2} \mathrm{~s}^{-1}, p=0.003\right)$. The erosion rate at $1.0 \mathrm{~N} \mathrm{~m}^{-2} \mathrm{~s}^{-1}$ was not measured at the mudflat in May 2000 as massive erosion occurred already at $0.5 \mathrm{~N} \mathrm{~m}^{-2}$.

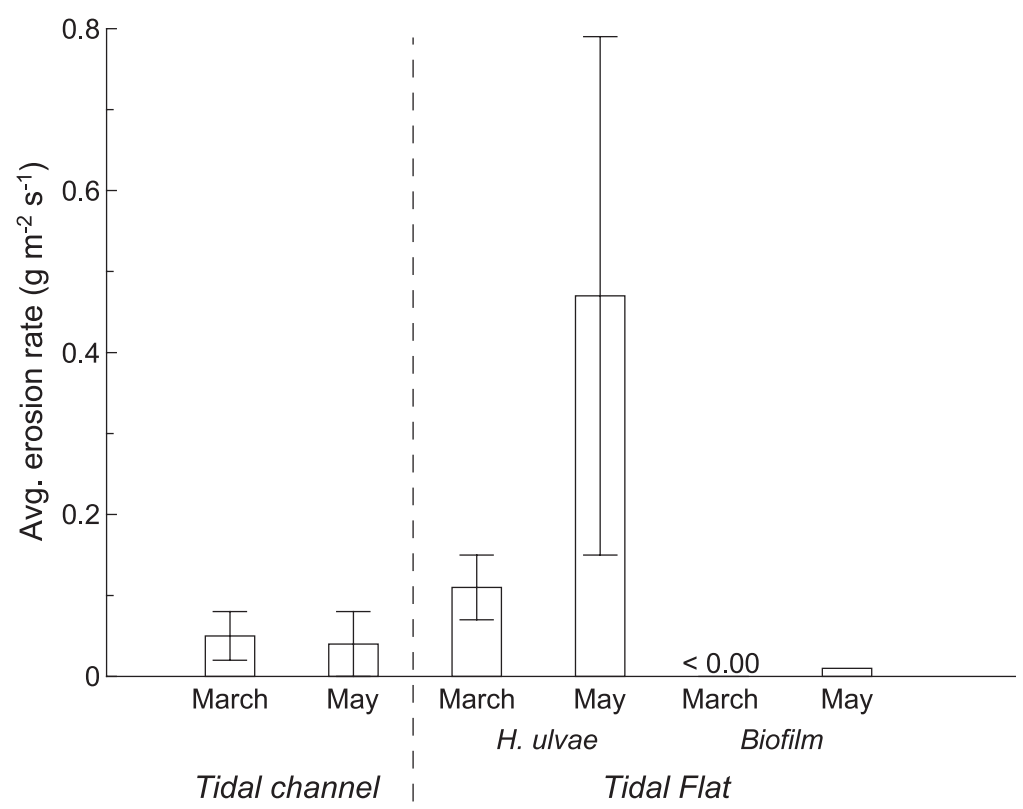

Fig. 7. Erosion rates at $0.5 \mathrm{~N} \mathrm{~m}^{-2}$ measured in the tidal channel $(n=8)$ and at the mudflat. The mudflat data is split into two groups: the sites dominated by $H$. ulvae $(n=4)$ and the sites dominated by microphytobenthos $(n=3)$. Error bars: average \pm STD. 


\subsection{Settling velocities of eroded material}

The settling velocities of the bed-material eroded from the mudflat and the tidal channel were not significantly different in March 2002 (0.46 and 0.53 $\mathrm{mm} \mathrm{s}{ }^{-1}$, respectively, $p=0.43$, Fig. 8) despite the sandier material in the channel. In contrast to this, significantly different settling velocities $(p=0.01)$ were observed at the two sites in May 2000 with a settling velocity of $1.1 \mathrm{~mm} \mathrm{~s}^{-1}$ in the channel and $2.7 \mathrm{~mm} \mathrm{~s}^{-1}$ at the mudflat and the difference was caused by a significantly higher settling velocity at the mudflat in May 2000 compared to March 2002 $(p<0.001)$. A major difference between the two sites was that the mean settling velocity at the mudflat always was larger than the calculated settling velocity for the primary grains of the bed material whereas the opposite generally was the case in the tidal channel. This shows that the eroded material was highly aggregated at the mudflat and less aggregated in the tidal channel. The settling velocity after an applied bed shear stress of 0.5 and $1.0 \mathrm{~N}$ $\mathrm{m}^{-2}$ were not different at the mudflat whereas a slight tendency for increasing settling velocities was observed at increasing bed shear stresses in the tidal channel $\left(0.30\right.$ and $0.47 \mathrm{~mm} \mathrm{~s}^{-1}$ at 0.5 and $1.0 \mathrm{~N}$ $\mathrm{m}^{-2}$, respectively).

\section{Discussion}

The erodibility of the studied bed sediments was generally significantly modified by the biological communities at the sites. High erosion thresholds were found at the mudflat at places where biofilms were present whereas low thresholds and high erosion rates were found for sites dominated by faecal pellets originating from $H$. ulvae. Both formation of biofilms and pelletization of the bed material showed a temporal variation which supports previous results from the mudflat (Andersen, 2001a). In contrast, the erodibility of the tidal channel sediments did not show any significant temporal variation and the sediments seemed to be less affected by both macrozoobenthos and microphytobenthos. This is a result of the very small macrozoobenthic population at the site and limited availability of light for microphytobenthic growth due to the larger water depth and generally high turbidity of the water column.

The erosion thresholds found for the channel sediments were about twice as high as the mudflat sediments without biofilms. It is not possible to conclude what the reason is, due to strong biological interaction at the mudflat but it is possible that it is an effect of the higher dry bulk densities for the channel sediments as density has been shown to affect the

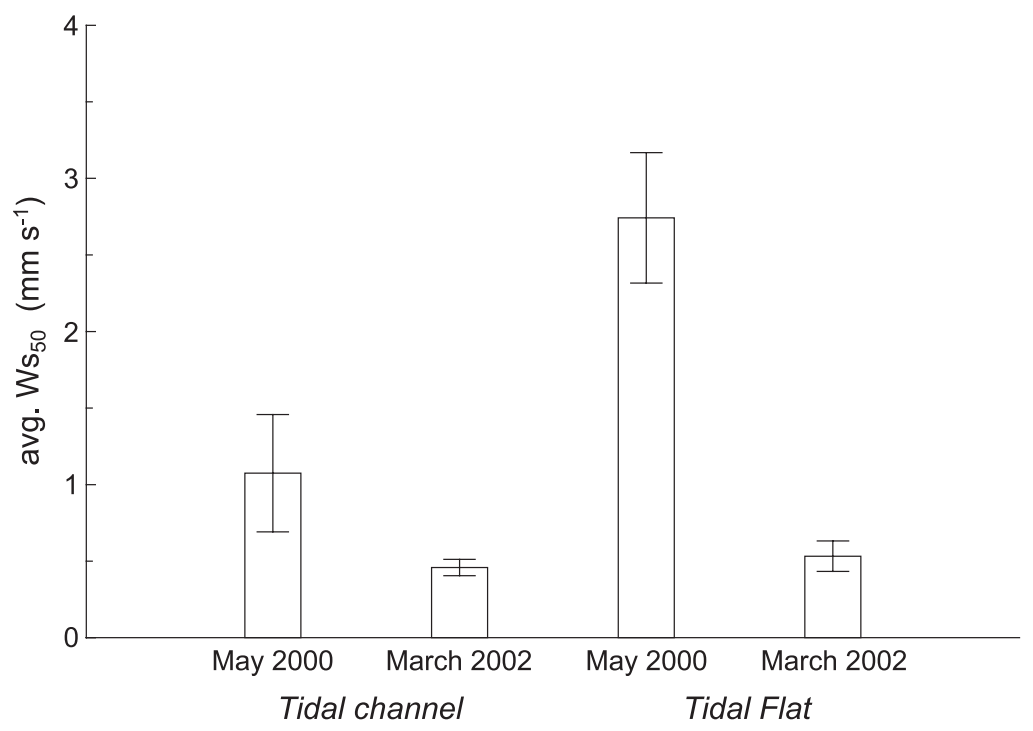

Fig. 8. The average settling velocity after $1.0 \mathrm{~N} \mathrm{~m}^{-2}$ in the tidal channel $(n=9$ and 6$)$ and $0.5 \mathrm{~N} \mathrm{~m}^{-2}$ at the mudflat $(n=5$ and 7$)$. Error bars: average \pm STD. 
erosion threshold of fine-grained sediments (e.g., Amos et al., 1997). However, reasonable densitythreshold relationships are only to be expected for sediments without significant biological mediation of the erodibility. When biofilms are present or the sediment is reworked by macrozoobenthos, any dependence on other physical parameters will generally by overshadowed (e.g., Widdows et al., 2000; Andersen, 2001a).

The erosion rate of the sediments showed very large variations with low rates found in the channel, at the mudflat in March and at mudflat sites dominated by biofilms. In contrast, sites with high density of $H$. ulvae mostly showed high erosion rates but no dependence on the number of snails was observed (Fig. 9a). However, a strong positive correlation was found between the faecal pellet content of the bed material (Fig. 9b) and the erosion rate, which shows that it is mainly the pelletization by the snail that affects the erodibility of the bed.

The weak dependence on the number of snails is due to the fact that the snail will quickly pelletize the bed even when present at comparatively low densities (Andersen et al., 2002) but it is the amount of readily suspended material (i.e., faecal pellets) which will determine the erosion rate. A strong seasonal variation in the faecal pellet content at the mudflat has been found (Andersen, 2001a) and this is causing the observed temporal variation in erosion rate at the mudflat sites dominated by $H$. ulvae.

It should be stressed that, whereas a quite large data-set of erodibility/settling measurements has been
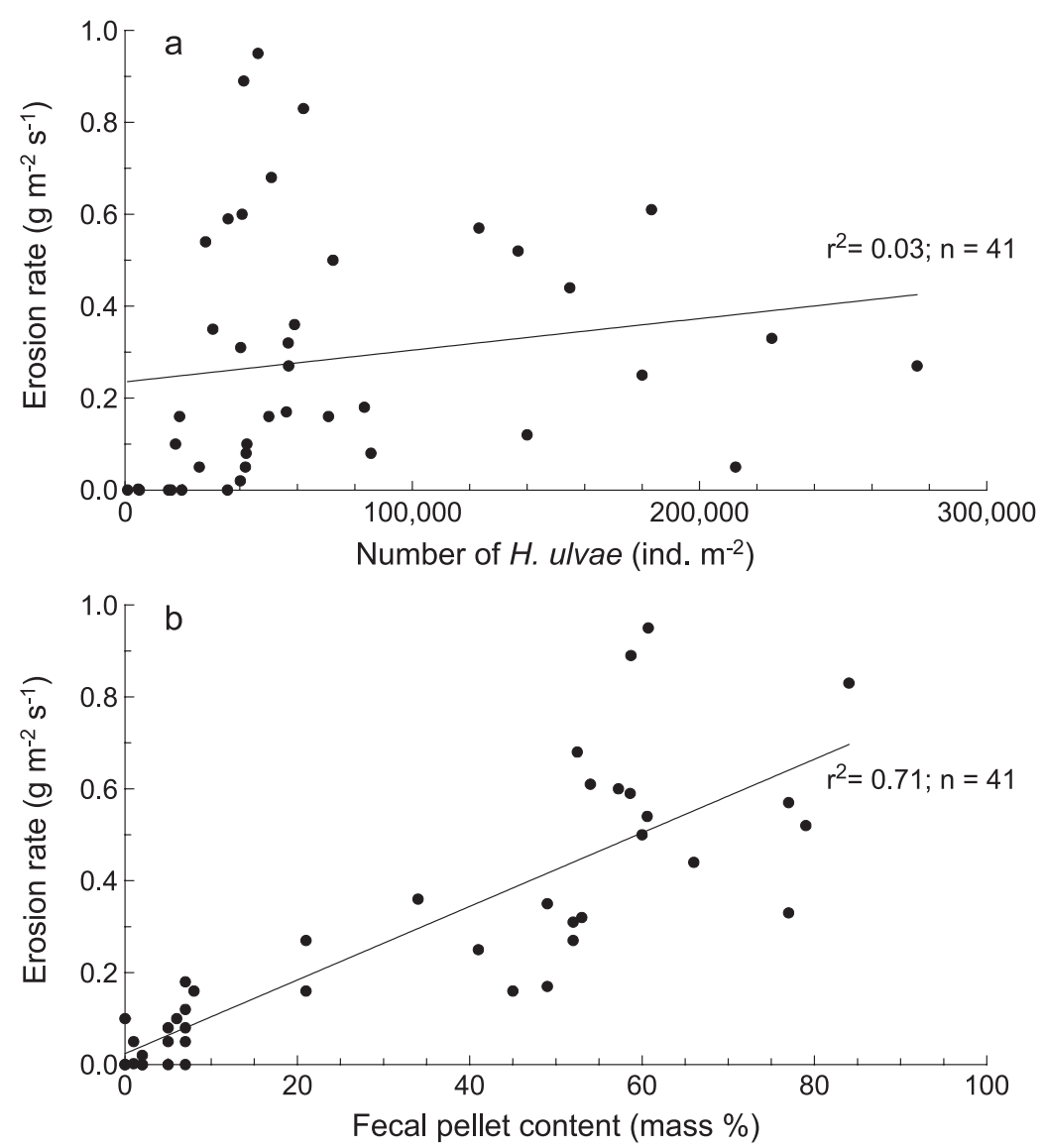

Fig. 9. The erosion rate at the mudflat plotted as a function of the density of H. ulvae (a) and the content of faecal pellets (b). Data from erosion experiments at the mudflat in 2000, 2001 and 2002 is included. 
collected from mudflat sites in the Danish Wadden Sea, only the two measuring campaigns reported here have been carried out in tidal channels. Consequently, it is possible (and likely) that other fine-grained channel-beds may show different characteristics as a result of different texture and/or biological community.

\subsection{Settling velocities of eroded bed-material}

Both temporal and spatial variations in the settling velocities of the eroded bed material were observed. Andersen and Pejrup (2002) showed that the settling velocities at the mudflat was strongly dependent on the content of faecal pellets and a strong seasonality was also found with higher settling velocities in the warmer seasons when pellets are very abundant. The seasonal variation is apparently far less pronounced in the tidal channel because the seasonality of the faecal pellet content is much smaller here compared to the mudflat where most of the pellets are produced. The settling velocities of the eroded material were more than twice as high at the mudflat than in the tidal channel in May 2000. Based on the data on seasonality presented by Andersen and Pejrup (2002), it is anticipated that a difference in settling velocity of this order is present in the months April-October due to the higher settling velocities at the mudflat in this period and a much smaller difference can be expected for the rest of the year.

\subsection{Seasonal and spatial variation of erosion and deposition}

The temporal variation of the mud-content of the bed material in the subtidal parts of Rømø Bay in 2002 (high contents at several stations in March 2002 but low during the other sampling periods, Fig. 4) showed that large amounts of fine-grained, mobile sediment were present in the tidal basin. The muddy sediments found in March 2002 were fresh deposits (aerobic and low density) and it seems most likely that this material was deposited on the sandy channel-bed during late winter/early spring and later eroded again during the summer when sandy deposits again were found. Temperature-adjustment of the sediment distribution due to seasonal variations in kinematic viscosity as discussed by Kroegel and Flemming (1998) does not seem to be the reason for this temporal pattern as a summer-increase in mud-content then would be expected. Accordingly, other processes must be responsible.

Bed-level data from the main part of the Kongsmark mudflat showed general erosion during spring 2002 and strong accumulation during the summer 2002 (Fig. 2). So far, no direct measurements of the bed-level changes in the tidal channel have been possible but the muddy sediment found in March was clearly recently deposited whereas the sandier material is likely to be lag sediments found after erosion of the channel bed. Consequently, there is some indication that the general net-transport of cohesive sediment in 2002 was from the mudflat to the tidal channel in late winter/early spring and vice versa in the summer period (Fig. 10). Seasonal changes in both physical and biological parameters may explain this transport pattern. The winter-period was characterized by mild weather with strong winds, which will increase the wave-induced erosion at the mudflat where waves completely dominate the erosion of the material. Ice formation, which may tend to protect the mudflat against erosion (Staats et al., 2001), did not occur this winter and this may also have enhanced the erosion at the flat. However, seasonal changes in the biological activity at the mudflat may also play a significant role as the pelletization discussed above will tend to trap material at the mudflat except for the cold seasons were biological activity and hence pelletization is low. Consequently, the reason for the net-erosion at the mudflat during winter/early spring was probably both increased hydrodynamic forces and the fact that the settling velocity of the eroded material was reduced substantially due to the low faecal pellet content. This will make the material more mobile in this low-energy environment. The data on the mudcontent in the tidal channel in spring 2002 suggests that at least some of the material eroded at the mudflat was deposited here temporarily. This is probably due to the fact that wind-waves do not play any significant role in the tidal channels (Lumborg et al., in prep.) and the inner parts of tidal channels (i.e., areas with low current velocities) will consequently show relatively low bed shear stresses, which favours net-deposition. Material will still be resuspended from the channel bed but the net-result during winter/early spring will 

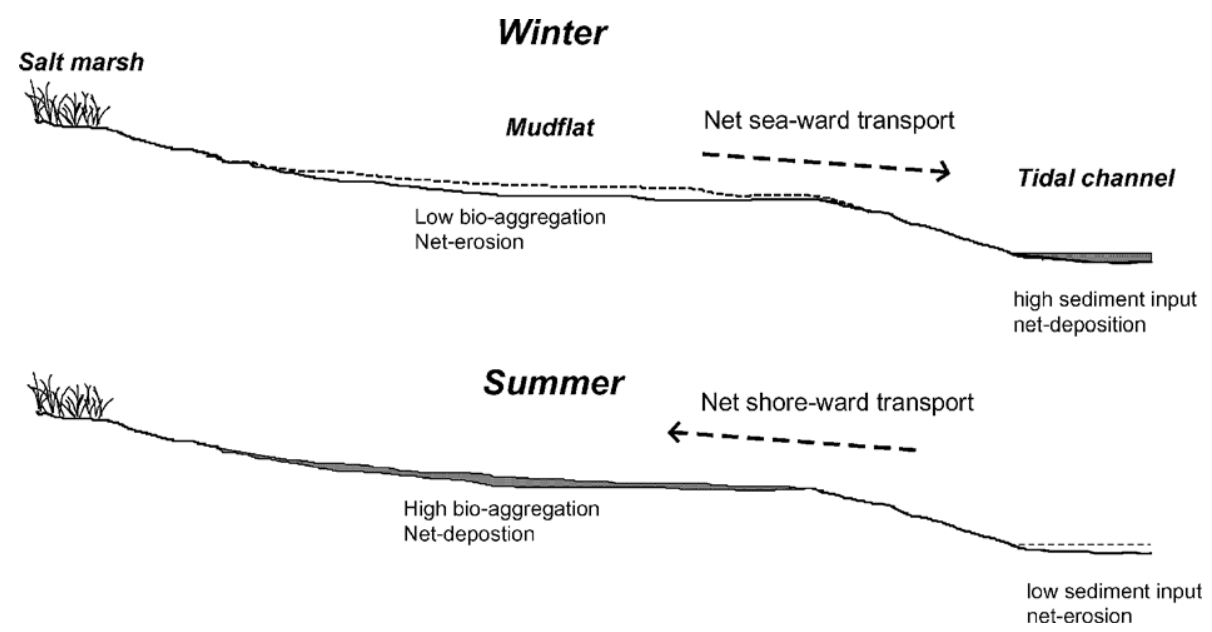

Fig. 10. The conceptual model showing the general net-transport direction of fine-grained sediment during winter and summer. Low biological activity at the mudflat during the winter causes a net sea-ward transport, whereas the higher biological activity in the summer reverses the nettransport direction.

be deposition due to the strong input of material form the mudflat.

As the water temperature increases during spring and summer, the biological activity and faecal pellet production increase dramatically at the mudflat. Periods of strong winds in the area will also be less frequent (Aagaard et al., 1995) and the mudflat will tend to trap material again (Fig. 2b). The general trapping of fine-grained material at the mudflat during the warmer seasons enhances the tendency for net inward transport of fine-grained sediment, which will mainly take place due to the shoreward decrease in current velocities and increasing tidal asymmetry (Van Straaten and Kuenen, 1958; later quantified for a tidal basin fairly similar to Lister Dyb tidal basin by Bartholdy, 2000). This inward transport apparently depletes the tidal channel of mud as shown by the decrease in mud-content of channel sediments during the summer 2002.

The cyclic behaviour described above did not show up clearly the following winter and spring and the reason was probably that the winter 20022003 was colder than average with monthly mean temperatures below zero in both December, January and February. This resulted in ice-cover and shelter of the mudflat during long periods and generally weaker winds than normally observed. The data-set thus implies that the seasonality suggested above does not apply to years with cold winters which are observed on average every seventh year in Denmark.

The innermost 50 to $100 \mathrm{~m}$ of the mudflat generally shows bed-level changes which are in a phase opposite to the rest of the mudflat (Andersen and Pejrup, 2001). This is both due to sedimentation of ice-rafted material (Pejrup and Andersen, 2000) and due to the general dominance of microphytobenthos instead of macrozoobenthos. The difference in biological structure results in very different erodibility (Fig. 4-6), which may explain why some of the material eroded at the main part of the mudflat often is deposited at the upper part of the mudflat where the erodibility generally will be low due to microphytobenthic stabilisation.

There is some indication that the transport pattern suggested in Fig. 10 does not only apply to this specific area but may be of a more general nature. Seasonal variations of the bed level somewhat similar to the main part of the Kongsmark mudflat were found by Frostick and McCave (1979) in the Deben estuary (UK). They argued that the sediment was redistributed within the estuary and accumulated on the mudflats during spring and summer due to algae binding and later was eroded and transported to channel banks in autumn and winter when algae were dead or absent. The present study gives some fielddata to support this idea and also shows how high densities of macrozoobenthos can significantly 
change the erodibility and aggregation of the bed material and how seasonal shifts in sediment erosion and deposition at least partly may be explained by variations in the biological activity at mudflats.

A coupling between macrozoobenthos and spatial variations of deposition/erosion was also found by Widdows et al. (2000) who argued that the deposition rate at a salt marsh in the Humber Estuary (UK) was affected by the changing density of the clam $M$. balthica at the fronting mudflat. Additionally, Wood and Widdows (2002) showed by simple numerical modelling for the same site that inter-annual variation in the abundance of the clam could change the net deposition by a factor of five. It is thus obvious from both this and other studies that biological interactions in the erosion, transport and deposition of fine-grained marine sediments may affect both the general nettransport of cohesive sediment and at places cause temporary shifts in deposition or erosion rates. However, as shown by Staats et al. (2001) simple relationships between the presence of, e.g., benthic diatoms and mud content do not exist and only by repeated measurements and with a good general understanding of a given sedimentary system is it possible to estimate if and to what extent the sediment transport is affected by the biological community structure.

\section{Acknowledgements}

This study was supported by the Danish Natural Science Research Council, grants no. 9701836 and 9901789. Our deepest thanks go to Dr. Karsten Reise, Alfred Wegener Institute of Polar and Marine Resources, Wattenmeerstation Sylt, Germany, and the captain and crew onboard the research vessel "Mya" for the opportunity to work on the subtidal parts of the tidal basin. T.J. Andersen benefited from financial support from the Carlsberg Foundation, grants no. ANS-0266/ 20 and ANS-0764/20. The comments from the anonymous reviewers are greatly appreciated.

\section{References}

Aagaard, T., Nielsen, N., Nielsen, J., 1995. Skallingen-origin and evolution of a barrier spit. Medd. Skalling-Lab. 35 (85 pp.).
Admiraal, W., 1984. The ecology of estuarine sediment-inhabitating diatoms. In: Round, F.E., Chapman, J. (Eds.), Progress in Physiological Research, vol. 3. Biopress, pp. 269-322.

Amos, C.L., Feeney, T., Sutherland, T.F., Luternauer, J.L., 1997. The stability of fine-grained sediments from the Fraser River Delta. Estuar. Coast. Shelf Sci. 45, 507-524.

Andersen, T.J., 2001a. Seasonal variation in erodibility of two temperate, microtidal mudflats. Estuar. Coast. Shelf Sci. 53, $1-12$.

Andersen, T.J., 2001b. The role of faecal pellets in suspended sediment settling velocities at an intertidal mudflat, the Danish Wadden Sea. In: McAnally, W.H., Mehta, A.J. (Eds.), Coastal and Estuarine Fine Sediment Processes. Elsevier Science, pp. 387-401.

Andersen, T.J., Jensen, K.T., Lund-Hansen, L., Mouritzen, K.N., Pejrup, M., 2002. Enhanced erodibility of fine-grained marine sediments by Hydrobia ulvae. J. Sea Res. 48, 51-58.

Andersen, T.J., Pejrup, M., 2001. Suspended sediment transport on a temperate, microtidal mudflat, the Danish Wadden Sea. Mar. Geol. 173, 69-85.

Andersen, T.J., Pejrup, M., 2002. Biological mediation of the settling velocity of bed material eroded from an intertidal mudflat, the Danish Wadden Sea. Estuar. Coast. Shelf Sci. 54, $737-745$.

Austen, I., Andersen, T.J., Edelvang, K., 1999. The influence of benthic diatoms and invertebrates on the erodibility of an intertidal mudflat, the Danish Wadden Sea. Estuar. Coast. Shelf Sci. 49, 99-111.

Bartholdy, J., 2000. Processes controlling import of fine-grained sediment to tidal areas: a simulation model. In: Pye, K., Allen, J.R.L. (Eds.), Coastal and Estuarine Environments: Sedimentology, Geomorphology and Geoarchaeology. Special PublicationGeological Society of London, vol. 175, pp. 13-29.

Blanchard, G.F., Sauriau, P.-G., Cariou-Le Gall, V., Gouleau, D., Garet, M.-J., Olivier, F., 1997. Kinetics of tidal resuspension of microbiota: testing the effect of sediment cohesiveness and bioturbation using flume experiments. Mar. Ecol., Prog. Ser. 151, 17-25.

Christiansen, C., Edelvang, K., Emeis, K., Graf, G., Jahmlich, S., Kozuch, J., Laima, M., Leipe, T., Loffler, A., Lund-Hansen, L.C., Miltner, A., Pazdro, K., Pempkowiak, J., Shimmield, G., Smith, J., Smith, J., Voss, M., Witt, G., 2002. Material transport from the nearshore to the basinal environment in the southern Baltic Sea: I. Processes and mass estimates. J. Mar. Syst. 35, 133-150.

Christie, M.C., Dyer, K.R., Turner, P., 1999. Sediment flux and bed level measurements from a macro tidal mudflat. Estuar. Coast. Shelf Sci. 49 (5), 667-688.

de Brouwer, J.F.C., Bjelic, S., de Deckere, E.M.G.T., Stal, L.J., 2000. Interplay between biology and sedimentology in a mudflat (Biezelingse Ham, Westerschelde, The Netherlands). Cont. Shelf Res. 20, 1159-1177.

de Deckere, E.M.G.T., van de Koppel, J., Heip, C.H.R., 2000. The influence of Corophium volutator abundance on resuspension. Hydrobiology 426, 37-42.

de Deckere, E.M.G.T., Kornman, B.A., Staats, N., Termaat, G.R., de Winder, B., Stal, L.J, Heip, C.H.R., 2002. The seasonal 
dynamics of benthic (micro) organisms and extracellular carbohydrates in an intertidal mudflat and their effect on the concentration of suspended sediment. In: Winterwerp, J.C., Kranenburg, C. (Eds.), Fine Sediment Dynamics in the Marine Environment. Proceedings in Marine Science, vol. 5. Elsevier, Amsterdam, pp. 429-440.

Eisma, D., 1993. Suspended Matter in the Aquatic Environment. Springer-Verlag, Berlin. 318 pp.

Frostick, L.E., McCave, I.N., 1979. Seasonal shifts of sediment within an estuary mediated by algal growth. Estuar. Coast. Mar. Sci. 9, 569-576.

Gerdol, V., Hughes, R.G., 1994. Effect of Corophium volutator on the abundance of benthic diatoms, bacteria and sediment stability in 2 estuaries in southeastern England. Mar. Ecol., Prog. Ser. 114 (1-2), 109-115.

Kroegel, F., Flemming, B.W., 1998. Evidence for temperatureadjusted sediment distributions in the back-barrier tidal flats of the East Frisian Wadden Sea (southern North Sea). Tidalites: Processes and Products, Special Publication-SEPM, vol. 61 , pp. $43-52$.

Lund-Hansen, L.C., Christiansen, C., Laima, M.J.C., 2001. A new video controlled, hydraulically damped corer for sediment/water interaction studies. Mar. Georesour. Geotechnol. 19, 147-154.

Lund-Hansen, L.C., Laima, M., Mouritsen, K., Lam, N.N., Hai, D.N., 2002. Effects of benthic diatoms, fluff layer, and sediment conditions on critical shear stress in a non-tidal coastal environment. J. Mar. Biol. Assoc. U.K. 82, 929-936.

Mouritsen, K.N., Mouritsen, L.T., Jensen, K.T., 1998. Change of topography and sediment characteristics on an intertidal mudflat following mass-mortality of the amphipod Corophium volutator. J. Mar. Biol. Assoc. U.K. 78, 1167-1180.

Nowell, A.R.M., Jumars, P.A., Eckman, J.E., 1981. Effects of biological activity on the entrainment of marine sediments. Mar. Geol. 42, 133-153.

O'Brien, D.J., Whitehouse, R.J.S., Cramp, A., 2000. The cyclic development of a macrotidal mudflat on varying timescales. Cont. Shelf Res. 20, 1593-1619.

Parsons, T.R., Maita, Y., Lalli, C.M., 1984. A Manual of Chemical and Biological Methods for Seawater Analysis. Pergamon. 173 pp.

Paterson, D.M., 1989. Short-term changes in the erodibility of intertidal cohesive sediments related to the migratory behaviour of epipelic diatoms. Limnol. Oceanogr. 34, 223-234.

Pejrup, M., Andersen, T.J., 2000. The influence of ice flow on sediment transport, deposition and reworking in a temperate intertidal mudflat area, the Danish Wadden Sea. Cont. Shelf Res. $20,1621-1634$.
Pejrup, M., Larsen, M., Edelvang, K., 1997. A fine-grained sediment budget for the Sylt-Rømø tidal basin. Helgol. Meeresunters. 51, 1-15.

Reise, K., 1985. Tidal flat ecology - an experimental approach to species interaction. Ecol. Stud. 54 (199 pp.).

Rhoads, D.C., 1974. Organism-sediment relations on the muddy sea floor. Ocean. Mar. Biol. Ann. Rev. 12, 263-300.

Riethmüller, R., Heineke, M., Kuhl, H., Keuker-Rudiger, R., 2000. Chlorophyll a concentration as an index of sediment surface stabilisation by microphytobenthos? Cont. Shelf Res. 20 (1011), 1351-1372.

Schünemann, M., Kühl, H., 1991. A device for erosion-measurements on naturally formed, muddy sediments: the EROMESSystem. Report of GKSS Research centre GKSS 91/E/18. 28 pp.

Staats, N., de Deckere, E.M.G.T., de Winder, B., Stal, L.J., 2001. Spatial patterns of benthic diatoms, carbohydrates and mud on a tidal flat in the Ems-Dollard estuary. Hydrobiology 448, $107-115$.

Stal, L.J., 2003. Microphytobenthos, their extracelular polymeric substances, and the morphogenesis of intertidal sediments. Geomicrobiol. J. 20, 463-478.

Underwood, G.J.C., Paterson, D.M., 1993. Seasonal changes in diatom biomass, sediment stability and biogenic stabilization in the Severn Estuary. J. Mar. Biol. Assoc. U.K. 73, 871-887.

Van Straaten, L.M.J.U., Kuenen, Ph.H., 1958. Tidal action as a cause of clay accumulation. J. Sediment. Petrol. 28, 406-413.

Widdows, J., Brinsley, M., 2002. Impact of biotic and abiotic processes on sediment dynamics and the consequences to the structure and functioning of the intertidal zone. J. Sea Res. 48 (2), $143-156$.

Widdows, J., Brinsley, M., Salkeld, P.N., Lucas, C.H., 2000. Influence of biota on spatial and temporal variation in sediment erodability and material flux on a tidal flat (Westerschelde, The Netherlands). Mar. Ecol., Prog. Ser. 194, 23-37.

Willows, R.I., Widdows, J., Wood, R.G., 1998. Influence of an infaunal bivalve on the erosion of an intertidal cohesive sediment: a flume and modelling study. Limnol. Oceanogr. 43, $1332-1343$.

Wood, R., Widdows, J., 2002. A model of sediment transport over an intertidal transect, comparing the influences of biological and physical factors. Limnol. Oceanogr. 74, 848-855.

Yallop, M.L., de Winder, B., Paterson, D.M., Stal, L.J., 1994. Comparative structure, primary production and biogenic stabilization of cohesive and non-cohesive marine sediments inhabited by microphytobenthos. Estuar. Coast. Shelf Sci. 39, $565-582$. 